\section{GEOCHEMISTRY \\ Minerals mimic synthetic structure}

Researchers have found naturally occurring metalorganic frameworks (MOFs) - chemical structures that were thought to exist only when made in the lab.

MOFs have open, porous architectures, which could make them useful in catalysis, photovoltaics and other applications. Tomislav Friščić at McGill University in Montreal, Canada, Sergey Krivovichev at Saint Petersburg State University in Russia and their colleagues used X-ray diffraction to study two samples from a permafrost drill core, which was taken from a Siberian coal mine 230 metres below Earth's surface more than 70 years ago. They observed that the rare organic minerals stepanovite and zhemchuzhnikovite contain channels, pores and other structures that are found in synthetic MOFs.

These are the only organic minerals known so far to have open architectures, the authors say.

Sci. Adv. 2, e1600621 (2016)

\section{URBAN ECOLOGY}

\section{Insect mix high in rich areas}

The interiors of homes in affluent neighbourhoods host a wider diversity of insects and spiders than do those in less wealthy areas.

Neighbourhoods with a high income often have a higher diversity of plants and

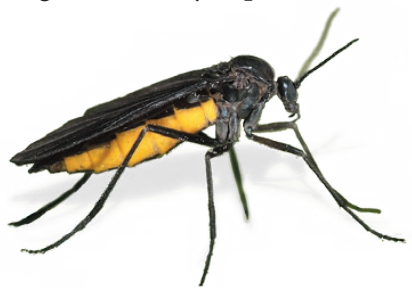

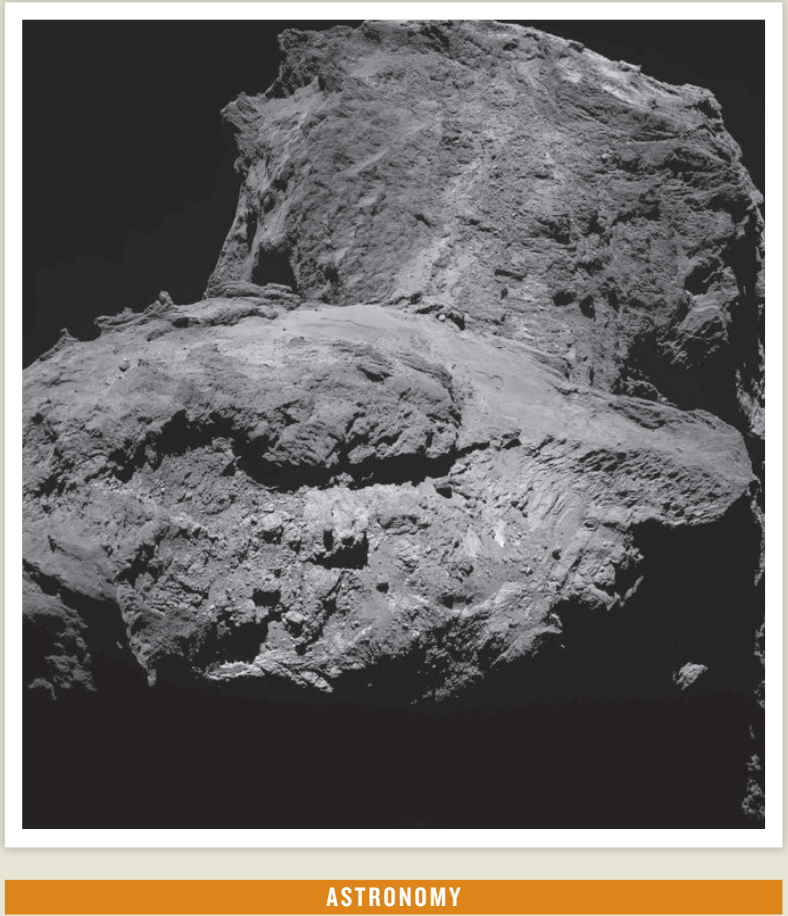

\title{
Gentle birth of a comet
}

The comet 67P/Churyumov-Gerasimenko (pictured), which has been orbited by the Rosetta spacecraft since 2014, might date back to the primordial Solar System billions of years ago. A team led by Björn Davidsson at NASA's Jet Propulsion Laboratory in Pasadena, California, used instruments on the European Space Agency's spacecraft to examine the structure of the comet's core. The porous consistency of 67P shows that it did not form through violent collisions. Instead, the authors propose that the comet was made gradually, when icy pebbles from the outer reaches of the developing Solar System clumped together. The two lobes of 67P may have gently joined together during the final stages of the comet's formation.

Astron. Astrophys. 592, A63 (2016)

certain animals, such as birds, than other areas. To find out whether this 'luxury effect' extends indoors, Misha Leong at the California Academy of Sciences in San Francisco and her colleagues sampled all arthropods - living and dead - including insects (pictured is Sciara hemerobioides), spiders and millipedes, inside 50 homes in and around Raleigh, North Carolina. They found that arthropod diversity increased with house size and diversity of surrounding vegetation, and were surprised to find a strong influence of average neighbourhood income, too.

Affluence could be affecting arthropod diversity through urban planning and landscaping at the neighbourhood level. Biol. Lett. 12, 20160322 (2016)
PALAEOECOLOGY

\section{Thirst finished off the mammoths}

One of the last woolly mammoth populations died out on an island off the coast of Alaska nearly 6,000 years ago, probably because of a shrinking supply of fresh water.

Human hunting has been linked to the extinction of the species (Mammuthus primigenius), but this relict population perished without our help, according to Russell Graham of Pennsylvania State University in University Park and his colleagues. The authors examined ancient DNA, isotopes and plant and animal material in sediment cores from a lake on St Paul Island. They also studied mammoth fossils. The researchers estimate that the island's mammoths became extinct 5,600 years ago, when the island was shrinking because of sea-level rise and the lake was evaporating into a salty puddle - perhaps because of long-standing drought, or depletion by the mammoths themselves.

Freshwater scarcity could drive island extinctions more often than previously thought, the authors say - and will only increase as the climate changes.

Proc. Natl Acad. Sci. USA http://doi.org/bm9z (2016)

\section{PARTICLE PHYSICS}

\section{No sign of new neutrino}

A massive detector at the South Pole has found no evidence of a 'sterile' neutrino: a nearmassless particle that is thought to interact only through gravity.

Hints of this possible fourth type of neutrino first emerged in the 1990s, and were rekindled early this year by an experiment in China. In the latest work, researchers 
at the IceCube Neutrino Observatory in Antarctica, led by Francis Halzen at the University of WisconsinMadison, counted neutrinos of a known type that hit the detector from below. A dearth of these neutrinos at particular energies would have revealed that some of the particles had temporarily mutated into sterile neutrinos during their trip through Earth, but the researchers found no such feature in their data.

The experiment did not rule out the existence of heavier sterile neutrinos. A fourth kind of neutrino would challenge the standard model of particle physics, which allows for only three neutrino types.

Phys. Rev. Lett. 117, 071801 (2016)

\section{EVOLUTION}

\section{Ancient whales heard high notes}

Fossil evidence suggests that the first whales could detect high-frequency sounds.

Researchers have

debated whether animals called archaeocetes - the common ancestors of all modern whales and dolphins - specialized in hearing high frequencies, like modern killer whales, or low frequencies, like today's humpback whales. Morgan Churchill at the New York Institute of Technology in Old Westbury and his colleagues describe a new species of whale (fossil skull pictured) dating from 27 million to 24 million years ago. Features of its remarkably wellpreserved inner ear, as well as other structures, suggest that the animal could generate

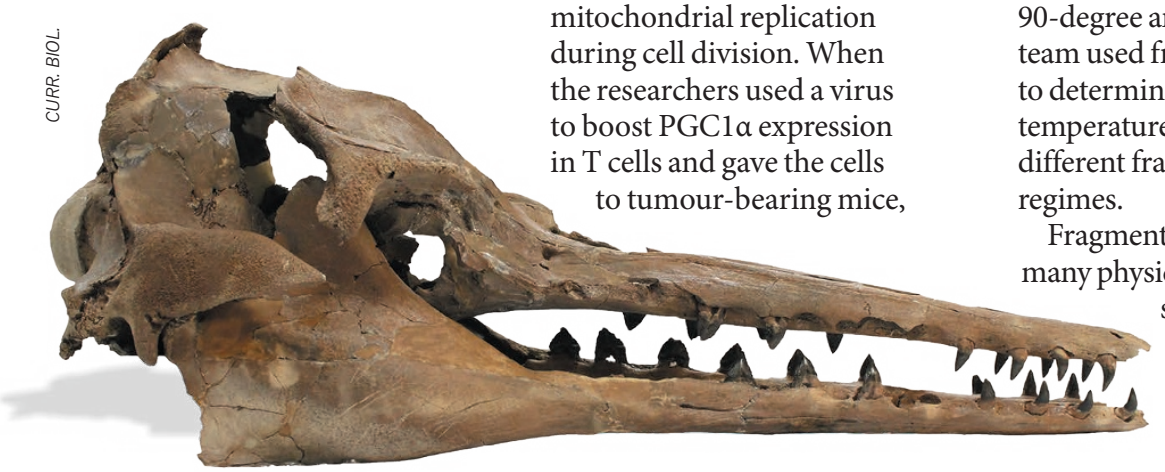

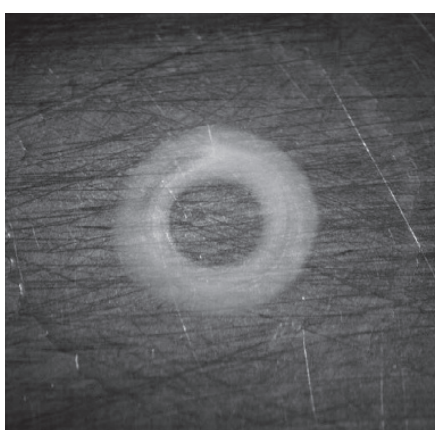

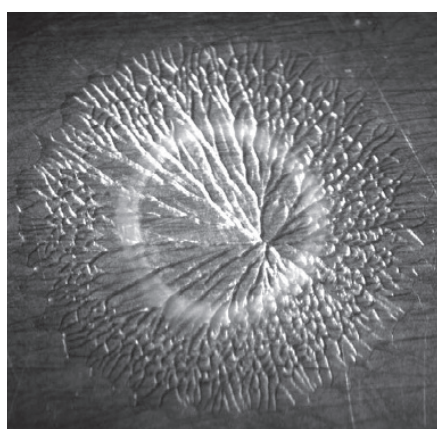

and hear high-frequency sounds. The inner ear also has primitive features similar to those of archaeocetes.

The authors suggest that the first whales could hear higher frequencies than their terrestrial ancestors — an ability co-opted by later toothed whales for echolocation.

Curr. Biol. http://doi.org/bnh5 (2016)

CANCER IMMUNOLOGY

\section{Immune cells tire} out in tumours

After they invade tumours, immune cells gradually lose their ability to produce energy.

Greg Delgoffe and his colleagues at the University of Pittsburgh in Pennsylvania studied immune cells called T cells in mice with implanted tumours. They found that T cells inside tumours were less effective at taking up glucose than those in other parts of the body. The tumour-infiltrating cells also showed reduced total mass of mitochondria - cell organelles that produce energy - and contained abnormally shaped mitochondria. The metabolic defects were linked to reduced levels of PGC1 $\alpha$, a protein that regulates mitochondrial replication during cell division. When the researchers used a virus to boost PGC1a expression T cells and gave the cells to tumour-bearing mice the tumours shrank more and the animals lived longer than those that received nonreprogrammed cells.

Boosting metabolic processes in immune cells could help to improve cancer therapies, the authors say. Immunity http://doi.org/bndn (2016)

\section{Crack patterns in freezing water}

Water droplets landing on a cold surface fragment into one of two different patterns as they freeze, depending on the temperature of the surface.

Elisabeth Ghabache and her colleagues at the University of Pierre and Marie Curie in Paris used a high-speed camera to monitor the behaviour of pancake-shaped water droplets that froze on a cold steel surface after being dropped from a height of 36 centimetres. They observed no crack formation when the surface was at $-20^{\circ} \mathrm{C}$ (pictured left). At $-30^{\circ} \mathrm{C}$ and $-40^{\circ} \mathrm{C}$, cracks spread from a central point towards the 'pancake' edge (centre). At $-50^{\circ} \mathrm{C}$ and $-60^{\circ} \mathrm{C}$, the cracking occurred in a step-by-step manner, with the initial cracks splitting into newer ones at roughly 90-degree angles (right). The team used fracture modelling to determine the transition temperatures between the frerent fragmentation

Fragmentation occurs in such as bubble bursting and glass breaking. This model system

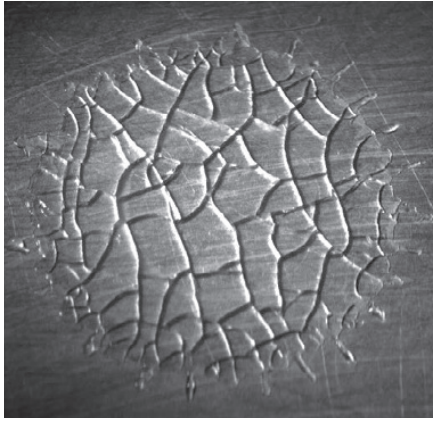

could help researchers to learn more about various fracture mechanisms, the authors say. Phys. Rev. Lett. http://dx.doi.org/ 10.1103/physrevlett.117.074501 (2016)

\section{MICROBIOLOGY}

\section{Toxic bacteria adapt fast}

Harmful blue-green algae can adapt rapidly to changing environments.

The photosynthetic cyanobacterium Microcystis produces toxic blooms in lakes and reservoirs. To test how different strains respond to changing carbon dioxide levels in water, Jef Huisman and his colleagues at the University of Amsterdam kept mixed populations in the laboratory and aerated the water with bubbles containing low or elevated levels of $\mathrm{CO}_{2}$. In low $\mathrm{CO}_{2}$ conditions, strains whose carbon-uptake systems are efficient when carbon is limited became dominant. When $\mathrm{CO}_{2}$ was elevated, however, strains that have systems with high uptake rates outcompeted the others. The team studied Microcystis collected from Lake Kennemermeer in the Netherlands and found that the abundance of each strain shifted with seasonal changes in $\mathrm{CO}_{2}$ availability.

Cyanobacteria may be more adept at dealing with high $\mathrm{CO}_{2}$ levels than previously thought. Proc. Natl Acad. Sci. USA http://doi.org/bnf9 (2016)

\section{$\rightarrow$ NATURE.COM}

For the latest research published by Naturevisit:

www.nature.com/latestresearch 